\title{
Baicalin, a natural compound, promotes regulatory $T$ cell differentiation
}

Ji Yang ${ }^{1 \dagger}$, Xue Yang ${ }^{2 \dagger}$ and Ming $\mathrm{Li}^{1^{*}}$

\begin{abstract}
Background: $\mathrm{CD}^{+} \mathrm{CD} 25^{+} \mathrm{Foxp}^{+}$regulatory $\mathrm{T}\left(\mathrm{T}_{\text {reg }}\right)$ cells inhibit autoimmunity and protect against tissue injury. The development of these $T_{\text {reg }}$ cells is controlled by the regulator protein Foxp3, which can be enhanced by the in vitro activation of Foxp3 in the presence of transforming growth factor-beta. However, little is known about alternative methods, such as the use of natural products, for controlling Foxp3-mediated $T_{\text {reg }}$ cell differentiation.

Method: HEK 293 T cells were transfected with Foxp3 expression plasmid, and then treated with different compounds, Foxp3 mRNA expression was determined by real-time RT-PCR. CD4 ${ }^{+} C D 25^{-T}$ cells were stimulated with Baicalin, Foxp3 protein expression were analyzed by flow cytometry and confocal microscopy, the regulatory function of $T$ cells stimulated with Baicalin was detected by the carboxyfluorescien succinimidyl ester.
\end{abstract}

Results: We demonstrated that Baicalin, a compound isolated from the Chinese herb Huangqin, induced Foxp3 protein expression in cultured $T$ cells, promoted $T_{\text {reg }}$ cell differentiation and regulatory activity. Our data also indicated that Baicalin restored Foxp3 expression following its initial interleukin-6-mediated inhibition and induced Foxp3 expression in vitro.

Conclusions: These data suggest that Baicalin may promote $T_{\text {reg }}$ cell differentiation and regulatory activity and may serve as a promising natural immunosuppressive compound for treating autoimmune inflammatory diseases.

Keyword: Baicalin, Foxp3, Treg cells

\section{Background}

$\mathrm{CD} 4^{+} \mathrm{CD} 25^{+} \mathrm{Foxp}^{+}$regulatory $\mathrm{T}$ (Treg) cells are essential for maintaining self-tolerance $[1,2]$ and play key roles in regulating immune system homeostasis [2]. Increasing evidence suggests that $T_{\text {reg }}$ cells are capable of inhibiting the function of Th1, Th2, Th17, and other effector cells; inhibiting inflammation and preventing autoimmunity $[3,4]$; therefore, the loss or dysfunction of $\mathrm{T}_{\text {reg }}$ cells often leads to autoimmune diseases such as systemic lupus erythematosus [5] , type I diabetes and inflammatory bowel disease $[2,6]$. The development and functions of $\mathrm{T}_{\text {reg }}$ cells are driven by the forkhead/winged-helix transcription factor Foxp3 [7-9], whose important role in $\mathrm{T}_{\text {reg }}$ cell activity was

\footnotetext{
*Correspondence: li.ming@zs-hospital.sh.cn

${ }^{\dagger}$ Equal contributors

'Department of Dermatology, Zhongshan Hospital, Fudan University,

Shanghai 200032, China

Full list of author information is available at the end of the article
}

previously demonstrated when mice expression mutant Foxp3 exhibited impaired $\mathrm{T}_{\text {reg }}$ cell activity and succumbed to a fatal lymphoproliferative disorder, which was then reversed by the transgenic expression of wild-type Foxp3 in these animals [10].

$\mathrm{T}_{\text {reg }}$ cells typically develop and proliferate in the thymus upon contact with self-antigen and are then transported to the peripheral immune system [2]. Several factors affecting $\mathrm{T}_{\text {reg }}$ cell homeostasis have been defined: for example, $\mathrm{T}_{\text {reg }}$ cell activity is interleukin (IL)-2-dependent [11]. In addition, $\mathrm{T}_{\text {reg }}$ cell activity can be induced in the peripheral immune system by the conversion of naïve $\mathrm{CD} 4^{+}$Foxp $3^{-} \mathrm{T}$ cells into Foxp $^{+} \mathrm{T}$ cells by transforming growth factor-beta (TGF- $\beta$ ) [4], which also maintains Foxp3 expression and can regulate the functions of $\mathrm{T}_{\text {reg }}$ cells [12]. Foxp3 is essential for the development and function of $\mathrm{CD} 4^{+} \mathrm{CD} 25^{+}$regulatory $\mathrm{T}$ cells [13], induction of the transcription factor Foxp3 can converse $\mathrm{CD} 4{ }^{+} \mathrm{CD} 25^{-}$naïve $\mathrm{T}$ cells to $\mathrm{CD} 4^{+} \mathrm{CD} 25^{+}$regulatory $\mathrm{T}$ 
cells [14]. In addition, Foxp3 solidifies $\mathrm{T}_{\text {reg }}$ cell lineage and amplifies the pre-established $\mathrm{T}_{\text {reg }}$ cells [7]. The effect of Foxp3 is to suppress the activation of target genes on $\mathrm{T}$ cell stimulation, as well as inhibit the production of interleukin (IL)-2, therefore Foxp3 is crucial for the normal function of $\mathrm{T}_{\text {reg }}$ cells [15]. Thus induction of Foxp3 expression and promotion of $\mathrm{T}_{\text {reg }}$ cells differentiation might be a promising therapeutic method for the treatment of autoimmunity diseases.

Recently, the vitamin A metabolite all-trans retinoic acid was shown to enhance TGF- $\beta$-mediated induction of Foxp3 [16-18]. In traditional Chinese medicine, some herbs are used in various anti-inflammatory applications [19-22], such as the treatment of autoimmune diseases, by suppressing effector T-cell reactions [23]; however, little is known about the role of natural compounds in controlling the differentiation and functions of $\mathrm{T}_{\text {reg }}$ cells. Since $\mathrm{T}_{\text {reg }}$ cells regulate the functions of effector $\mathrm{T}$ cells, we hypothesized that some therapeutic herbs may suppress inflammation by promoting Foxp3-mediated $\mathrm{T}_{\text {reg }}$ cell differentiation and thus controlling effector $\mathrm{T}$ cell activities. To support this, previous study showed that berberine, an isoquinoline alkaloid derived from plants, inhibited differentiation of Th17 cells and, to a lesser degree, Th1 cells, whereas it had no effect on the relative number of $\mathrm{CD}^{+}{ }^{+} \mathrm{Foxp}^{+}$regulatory $\mathrm{T}$ cells in the experimental autoimmune encephalomyelitis mice [19]. Artemisinin analog SM934 had therapeutic effects in lupus-prone female MRL/lpr mice by inhibiting both Th1 cell and Th17 cell responses, and elevated the percentage of Treg cells ex vivo, but not Treg cells in vitro[22].

In this study, we selected herbs for the development of Treg cells, two criteria are considered: the herb must be safe for patient use, and the chemical structures of the active ingredients of the herb must already be described. We demonstrated that Baicalin, a flavonoid compound originally isolated from the Chinese herb Huangqin (Scutellaria baicalensis Georgi), up-regulated Foxp3 mRNA expression in HEK $293 \mathrm{~T}$ cells and promoted $\mathrm{T}_{\text {reg }}$ cell differentiation. Furthermore, we showed that Baicalin could restore Foxp3 expression following its initial IL-6-mediated inhibition, Baicalin could also directly induce Foxp3 expression, promote $\mathrm{T}_{\text {reg }}$ cell differentiation and regulatory activity. Our findings indicate that Baicalin may be a promising natural immunosuppressive compound for treating inflammatory diseases.

\section{Methods}

Plasmids, cell lines, and transfection for Foxp3 mRNA expression studies

The Foxp3-IRES-GFP expression plasmid (pZIGF) and control plasmid were kindly provided by Wang Shengjun. HEK 293 T cells (Chinese Academy of Sciences, Shanghai, China) were maintained in Dulbecco's modified Eagle's medium (Hyclone, Logan, UT) and transiently transfected with pZIGF using Lipofectamine (Invitrogen, San Diego, CA). At $24 \mathrm{~h}$ post-transfection, HEK $293 \mathrm{~T}$ cells were treated with different compounds $(20 \mu \mathrm{M}$ Baicalin, $10 \mu \mathrm{M}$ Paeoniflorin, $0.5 \mathrm{ng} / \mathrm{ml}$ Triptolide, $1 \mu \mathrm{M}$ Artemerher, $5 \mu \mathrm{M}$ Cryptotanshinone, 30nM Retinoic acid, $10 \mu \mathrm{M}$ Sinomenine, or $10 \mu \mathrm{M}$ Paeonol; All compounds are from National Institute for the Control of Pharmaceutical and Biological Products, Beijing, China) for another $24 \mathrm{~h}$, and Foxp3 mRNA expression levels from cells in each group were determined by real-time reverse transcription-polymerase chain reaction (RT-PCR). For some experiments, HEK 293 T cells were treated with different doses of Baicalin or incubated with a constant dose of Baicalin $(20 \mu \mathrm{M})$ for various treatment times, and Foxp3 mRNA expression was analyzed by real-time RT-PCR. Where indicated, cultures were supplemented with 5 ng/ml TGF- $\beta$, 20 ng/ml IL-6 (PeproTech, Rocky Hill, NJ), $20 \mu \mathrm{M}$ Baicalin, or DMSO vehicle control, and Foxp3 mRNA expression was determined by RT-PCR.

\section{RNA isolation and real-time RT-PCR}

Total RNA from transfected HEK 293 T cells was prepared with the use of the Trizol reagent according to the manufacturer's protocol (Invitrogen). cDNA was synthesized with a first-strand cDNA synthesis kit and oligo (dT) primers (Fermentas, Hanover, MD), and gene expression was examined with a Bio-Rad iCycler Optical System (Bio-Rad, Richmond, CA) using a SYBR green real-time PCR Master Mix (Toyobo, Osaka, Japan). The 2- $\Delta \Delta \mathrm{Ct}$ method was used to normalize transcription levels to human $18 \mathrm{~S}$ or Mus $\beta$-actin and to calculate fold-changes in expression levels relative to controls. The primer pairs could be seen in Table 1.

Table 1 The following primer pairs were used

\begin{tabular}{llc}
\hline Gene & \multicolumn{1}{c}{ Forward (5'-3') } & Reverse (5'-3') \\
\hline Mus $\beta$-actin & GACGGCCAGGTCATCACTATTG & AGGAAGGCTGGAAAAGAGCC \\
Mus Foxp3 (239 T cell) & CTACCCACTGCTGGCAAATG & GCCTTGCCTTTCTCATCCA \\
Mus Foxp3 (T cell) & CCCAGGAAAGACAGCAACCTT & TTCCACAACAAGGCCACTTG \\
Human 18S & GCCCGAAGCGTTTACTTTGA & TCCATTATTCCTAGCTGCGGTATC \\
Human IL-6Ra & CATTGCCATTGTTCTGAGGTTC & AGTAGTCTGTATTGCTGAGGTTC \\
\hline
\end{tabular}


A

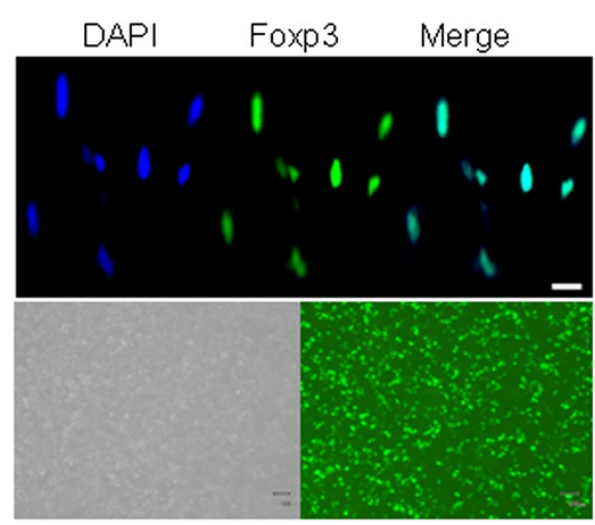

C

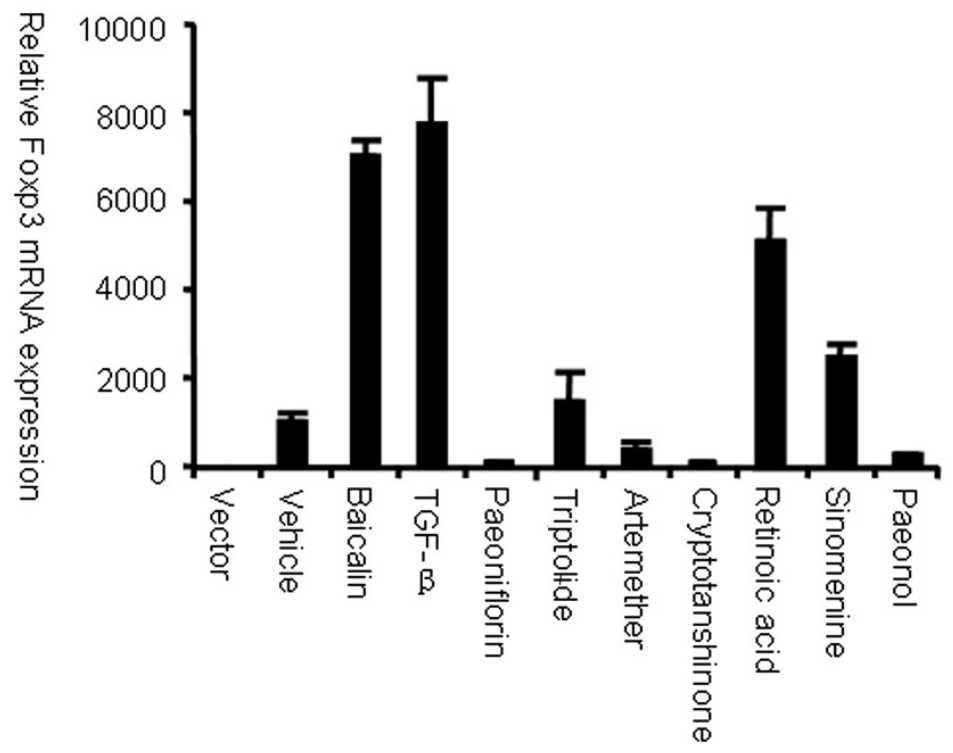

Figure 1 Screening of compounds that up-regulate Foxp3 expression. HEK 293 T cells were transfected with Foxp3 expression plasmids. (A) Nuclear expression of Foxp3 in HEK 293 T cells was examined by immunofluorescence microscopy. Scale bar, 10 um. (B) Foxp3 mRNA expression in transfected HEK 293 T cells was determined by RT-PCR. (C) Twenty-four hours after transfection, cells were then treated with different compounds for another $24 \mathrm{~h}$. Foxp3 mRNA expression was analyzed by real-time RT-PCR. Data are expressed as mean \pm SD, and compared with vector control (expression level of vector control was set as 1.0). Shown are results from three independent experiments.

\section{Mice, $\mathrm{CD}^{+}{ }^{+}$-cell isolation, and culture conditions}

Wild-type C57BL/6 (B6) mice were purchased from the Shanghai Laboratory Animal Center (Chinese Academy of Sciences). The animal protocol was approved by the Institutional Animal Use Committee of the Shanghai Institutes for Biological Sciences. All mice were maintained under pathogen-free conditions. Naïve $\mathrm{CD} 4^{+} \mathrm{CD} 25^{-} \mathrm{T}$ (FITC-conjugated anti-CD4 and PE-conjugated anti-CD25, eBioscience, San Diego, CA) cells from spleen of B6 mice were isolated by fluorescence-activated cell sorting (FACS). T cells were stimulated with $2 \mu \mathrm{g} / \mathrm{ml}$ plate-bound anti-CD3 and $2 \mu \mathrm{g} / \mathrm{ml}$ soluble anti-CD28 (eBioscience) for 3 days. Where indicated, cultured $\mathrm{T}$ cells were treated with different doses of Baicalin, and a DMSO-only control was used in some experiments. For some experiments, CD $4^{+} \mathrm{CD} 25^{-} \mathrm{T}$ cells were labeled by carboxyfluorescien succinimidyl ester (CFSE, Invitrogen), and co-cultured with $\mathrm{CD} 4{ }^{+} \mathrm{CD} 25^{+} \mathrm{T}$ cells in the presence of $20 \mu \mathrm{M}$ Baicalin for 5 days, the proliferation of $\mathrm{T}$ cells was analyzed by flow cytometry.

\section{Flow cytometry analysis and confocal microscopy}

Cells obtained from in vitro cultures were first stained with FITC-conjugated anti-CD4, PE-conjugated anti-CD25 (eBioscience). For Foxp3 staining, cells were treated with PE-Cy5-conjugated anti-Foxp3 according to the manufacturer's protocol (eBioscience). After staining, cells were 
analyzed in a FACS-Calibur flow cytometer (BD-Bioscience) using FlowJo software (Tree Star, San Carlos, CA). Cells were then visualized with a Leica TCS SP2 confocal microscope (Leica, Cambridge, UK), and fluorescence intensity data were measured using LCS Lite software (Leica). Five independent cells were selected randomly from each sample for analysis.

\section{Statistical analysis}

Quantitative data were expressed as means \pm standard deviation (SD). The statistical significance was determined by analysis of variance followed by a Bonferroni post-hoc test for multiple comparisons or the Student's t-test. All $p$ values $\leq 0.05$ were considered significant.

\section{Results}

Screening of compounds up-regulating Foxp3 expression To screen for natural compounds that up-regulate nuclear transcription factor Foxp3 expression in T cells, HEK $293 \mathrm{~T}$ cells were transiently transfected with the Foxp3-GFP expression plasmid pZIGF. Subsequent immunofluorescence microscopy showed the nuclear localization of Foxp3 in the cells (Figure 1A), which allowed us to accurately identify compounds that affect the gene expression of Foxp3. Real-time RT-PCR confirmed that Foxp3 mRNA expression levels were higher in pZIGF-transfected HEK 293 T cells when compared with vector-only control cells (Figure 1B). To identify novel compounds that up-regulate Foxp3 expression, the transfected HEK 293 T cells were then treated with different anti-inflammatory compounds isolated from Chinese herbs at concentrations that would not adversely affect cell proliferation (data not shown). Among the different compounds tested, Baicalin (7-glucuronic acid, 5, 6-dihydroxyflavone, molecular weight $=446.36)$ induced the highest expression of Foxp3 mRNA (Figure 1C). We confirmed this finding by stimulating HEK 293 T cells with combinations of TGF- $\beta$ and different herbal compounds and observed a synergistic effect of TGF- $\beta$ and Baicalin with respect to Foxp3 mRNA expression (data not shown).

\section{Baicalin up-regulates Foxp3 expression in HEK 293 T cells}

After transfection with pZIGF, HEK 293 T cells were treated with Baicalin, which resulted in both dose- and timedependent increases in the expression of Foxp3 mRNA (Figure $2 \mathrm{~A}$ and B). Because TGF- $\beta$ can induce the expression of Foxp3 and inflammatory cytokines such as IL-6 may inhibit its expression [24], we studied Baicalin's effects on Foxp3 expression in the presence of TGF- $\beta$ and IL- 6 . As expected, the addition of TGF- $\beta$ and IL- 6 to transfected cells inhibited Foxp3 mRNA expression, whereas the

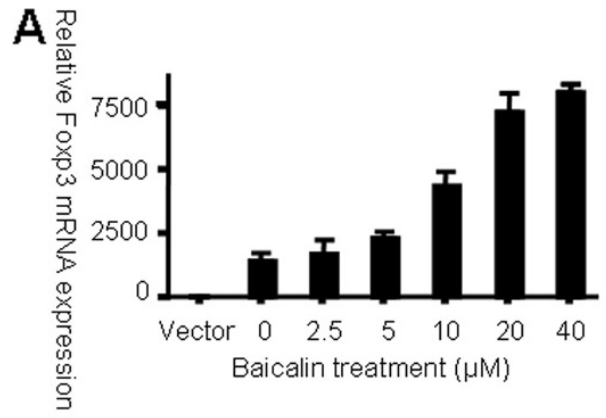

\section{$B$}
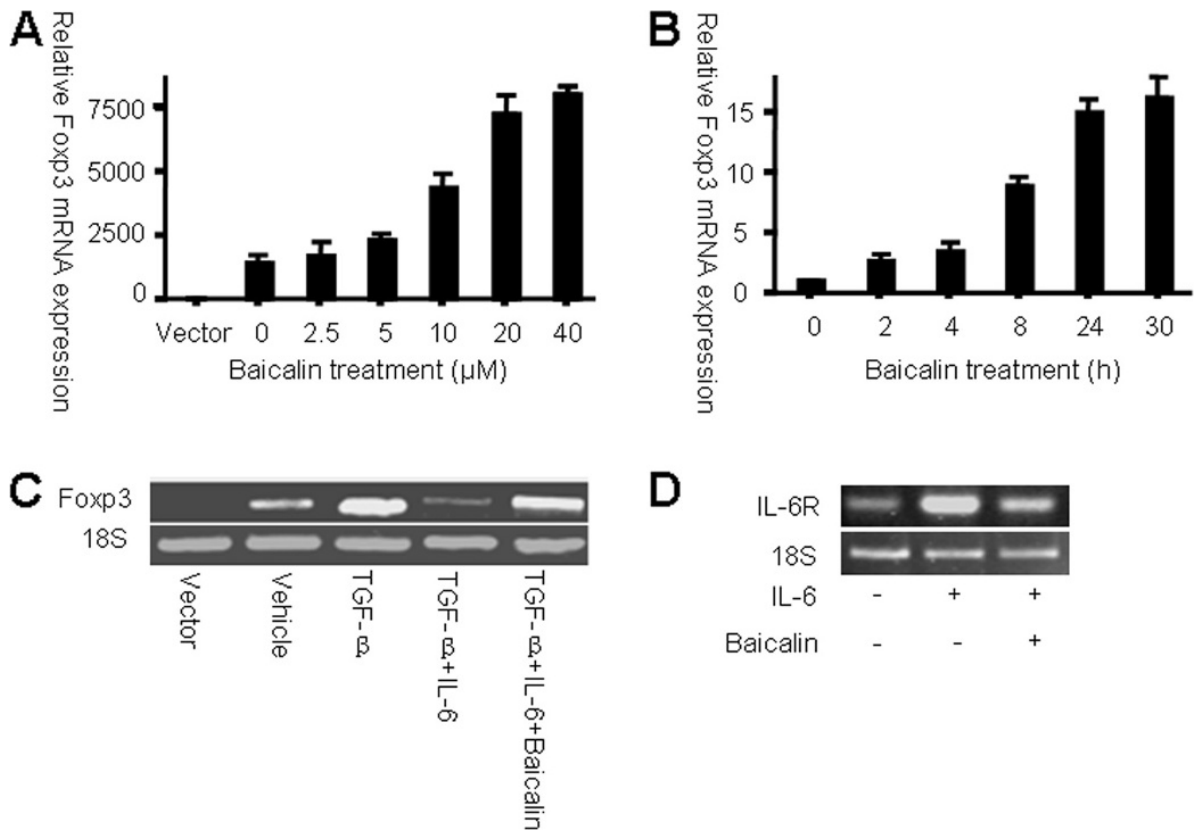

Figure 2 Baicalin up-regulates Foxp3 expression in HEK 293 T cells. Foxp3 mRNA levels in transfected HEK 293 T cells are shown (A) Twenty-four hours after transfection, cells were treated with Baicalin for another $24 \mathrm{~h}$. The dose-dependent induction of Foxp3 mRNA expression is shown. Date are expressed as mean \pm SD and compared with the vector control (expression level of the vector control was set as 1.0). (B) After transfection with Foxp3 expression plasmids, a second group of cells was treated with $20 \mu \mathrm{M}$ Baicalin. The time-dependent induction of Foxp3 mRNA expression is shown. Data are expressed as mean \pm SD (expression level at $0 \mathrm{~h}$ was set as 1.0). (C) Transfected HEK $293 \mathrm{~T}$ cells were treated with indicated cytokines in the presence or absence of Baicalin for another $24 \mathrm{~h}$. Foxp3 mRNA was examined by RT-PCR. (D) HEK 293 T cells were treated with IL-6 in the presence or absence of Baicalin for 24 h, and IL-6R mRNA levels were examined by RT-PCR. 
subsequent addition of Baicalin could restore Foxp3 expression (Figure $2 \mathrm{C}$ ) by countering the activity of IL-6. Furthermore, our data showed that treating transfected HEK $293 \mathrm{~T}$ cells with IL-6 could induce the expression of IL-6R mRNA and that treatment with Baicalin could inhibit IL-6 receptor mRNA expression (Figure 2D).

\section{Baicalin promotes Foxp3 expression in $\mathrm{CD} 4^{+} \mathrm{CD} 25^{-} \mathrm{T}$ cells}

To determine the effects of Baicalin on endogenous Foxp3 expression, $\mathrm{CD} 4^{+} \mathrm{CD} 25^{-} \mathrm{T}$ cells from wild-type $\mathrm{B} 6$ mice were sorted by FACS and activated with anti-CD3 and anti-CD28 antibodies in the presence of Baicalin. Our data showed that Baicalin could induce the differentiation of these $\mathrm{T}_{\text {reg }}$ cells in a dose-dependent manner (Figure 3A). Confocal microscopy of the activated cells revealed nuclear expression levels of Foxp3 protein in $\mathrm{CD} 4^{+} \mathrm{CD} 25^{-} \mathrm{T}$ cells after a 3-day treatment with Baicalin (Figure 3B, C). Further study showed that in the presence of Baicalin $\mathrm{CD} 4{ }^{+} \mathrm{CD} 25^{+} \mathrm{T}$ cells have stronger inhibition on the proliferation of effector T cells (Figure 3D). These data demonstrate that Baicalin could promote nuclear Foxp3 expression, induce CD $4^{+} \mathrm{CD} 25^{+} \mathrm{Foxp}^{+} \mathrm{T}_{\text {reg }}$ cell differention and strengthen the regulatory function.

\section{Discussion}

Baicalin, an active ingredient originally isolated from the root of the Chinese herb Huangqin (Scutellaria baicalensis Georgi), has been used as an anti-inflammatory drug in traditional Chinese medicine practices [25,26]. Previous studies have investigated Baicalin's mechanisms of action, revealing that Baicalin could suppress the production of inflammatory mediators such as IL-6 [25], bind to a variety of chemokines to limit their biological functions [27], and prevent leukocyte adhesion [28]. In addition, we have previously shown that Baicalin inhibited Th17 cell differentiation both in vitro and in vivo, Baicalin could restore IL-6mediated inhibition of Foxp3 [29]. But whether Baicalin could promote Foxp3 expression in the absence of TGF- $\beta$ is not clear, whether $\mathrm{T}_{\text {reg }}$ cells generated in the presence of Baicalin maintain regulatory activity is not known.

In the current study, we found that Baicalin up-regulated both exogenous and endogenous Foxp3 expression and

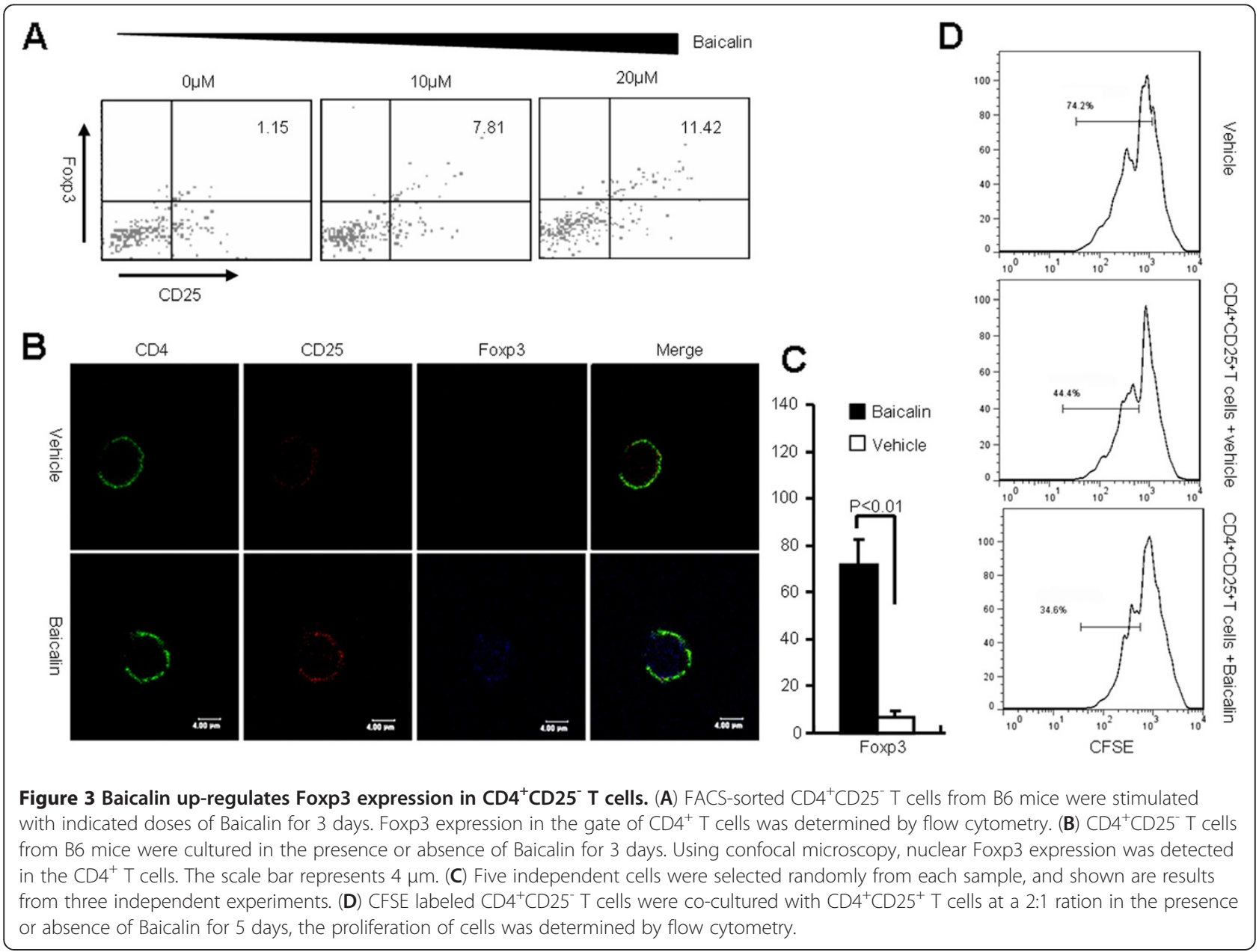


subsequently counteracted IL-6 mediated inhibition of Foxp3 expression, which confirmed previous findings that Foxp3 expression was restored after its initial suppression of specific pro-inflammatory cytokines [24]. TGF- $\beta$ induces the differentiation of $\mathrm{T}_{\text {reg }}$ cells, whereas IL-6 inhibits TGF$\beta$-induced generation of $\mathrm{T}_{\text {reg }}$ cells [17], and IL-6 blockade by treatment with an anti-IL-6R monoclonal antibody could promote $\mathrm{T}_{\text {reg }}$ cell differentiation [30]. Our data showed that Baicalin could inhibit IL-6R mRNA expression, which implied that Baicalin could restore IL-6-IL-6R-mediated inhibition of Foxp3 expression during $\mathrm{T}_{\text {reg }}$ cell differentiation. We further determined that Baicalin could directly upregulate the expression of Foxp3 in transfected HEK $293 \mathrm{~T}$ cells and cultured T lymphocytes in the absence of TGF- $\beta$. In addition, we confirmed that Baicalin induced the nuclear expression of Foxp3 and promote $\mathrm{T}_{\text {reg }}$ cell differentiation in vitro. $\mathrm{T}$ cells stimulated with Baicalin showed more powerful inhibition on the proliferation of effector $\mathrm{T}$ cells, which indicated the expression of Foxp3 is correlated to the $\mathrm{T}_{\text {reg }}$ cell activity. Although our data showed that Baicalin could directly promote Foxp3 expression in T cells, further investigations should explore the possible mechanisms, such as epigenetic regulation.

Autoimmune responses and homeostasis are maintained by a fine balance between effector $T$ and $T_{\text {reg }}$ cell activities. In patients with autoimmune diseases, the proliferation of effector $\mathrm{T}$ cells is directly related to the depletion and/or dysfunction of $\mathrm{T}_{\text {reg }}$ cells [31]. During an immune response, feedback regulators initiate and activate effector cell activities, so the exclusive inhibition of specific effector $\mathrm{T}$ cells may not effectively control the response. Therefore, for the treatment of autoimmune diseases, therapeutic agents that can regulate the relationship between effector $\mathrm{T}$ cells and $\mathrm{T}_{\text {reg }}$ cells rather than those that only regulate effector $\mathrm{T}$ cells are of great clinical interest [31]. Our data showed that Baicalin could promote $\mathrm{T}_{\text {reg }}$ cell differentiation and upregulate the regulatory function of $\mathrm{T}_{\text {reg }}$ cells in vitro, which imply that Baicalin might be used for the treatment of autoimmune diseases. Whereas further study should be done to elevate the role of Baicalin on the differentiation of Treg cells in vivo.

\section{Conclusions}

In this study, we demonstrated that Baicalin could enhance the expression of Foxp3, potentially promoting $\mathrm{T}_{\text {reg }}$ cell differentiation and activity in vitro. Specifically, the Foxp3-mediated induction of $\mathrm{T}_{\text {reg }}$ cells may control autoimmune diseases by eliminating inflammation caused by effector T cells; thus Baicalin might serve as a promising natural immunosuppressive compound for the treatment of autoimmune diseases.

\section{Competing interests}

The authors declare that they have no competing interests.

\section{Authors' contributions}

Ji Yang and Xue Yang carried out the cell culture, transfection and drafted the manuscript. Ji Yang and Xue Yang carried out molecular biology studies and immunoassays. Ji Yang, Xue Yang, and Ming Li participated in the design of the study and performed the statistical analysis. Ji Yang, Xue Yang, and Ming Li conceived of the study, and participated in its design and coordination. All authors read and approved the final manuscript.

\section{Acknowledgments}

We thank S.H. Sun for technical assistance and X.R.Yang, A.W. Ke, F.Y. Xiang, K.C. Li, X.B. Zhang, X. Zhang, L.B. Zhu, D. G, and Q.G. Wang for helpful discussions. This work was supported by grants from the National Natural Science Foundation of China (No. 81000693; 30872274; 81072463) and the Institutes of Biomedical Sciences of Fudan University (No. 2009068).

\section{Author details}

'Department of Dermatology, Zhongshan Hospital, Fudan University, Shanghai 200032, China. ${ }^{2}$ Division of Rheumatology, Huashan Hospital, Fudan University, Shanghai, China.

Received: 31 July 2011 Accepted: 5 March 2012

Published: 16 May 2012

\section{References}

1. Aluvihare VR, Kallikourdis M, Betz AG: Regulatory T cells mediate maternal tolerance to the fetus. Nat Immunol 2004, 5:266-271.

2. Sakaguchi S: Naturally arising Foxp3-expressing CD25+CD4+ regulatory T cells in immunological tolerance to self and non-self. Nat Immunol 2005, 6:345-352

3. Stummvoll GH, DiPaolo RJ, Huter EN, Davidson TS, Glass D, Ward JM, Shevach EM: Th1, Th2, and Th17 effector T cell-induced autoimmune gastritis differs in pathological pattern and in susceptibility to suppression by regulatory T cells. J Immunol 2008, 181:1908-1916.

4. Sakaguchi S: Naturally arising CD4+ regulatory t cells for immunologic self-tolerance and negative control of immune responses. Annu Rev Immunol 2004, 22:531-562

5. Yang J, Chu Y, Yang X, Gao D, Zhu L, Yang X, Wan L, Li M: Th17 and natural Treg cell population dynamics in systemic lupus erythematosus. Arthritis Rheum 2009, 60:1472-1483.

6. Glisic S, Klinker M, Waukau J, Jailwala P, Jana S, Basken J, Wang T, Alemzadeh R, Hagopian W, Ghosh S: Genetic association of HLA DQB1 with CD4 + CD25 + (high) T-cell apoptosis in type 1 diabetes. Genes Immun 2009, 10:334-340.

7. Gavin MA, Rasmussen JP, Fontenot JD, Vasta V, Manganiello VC, Beavo JA, Rudensky AY: Foxp3-dependent programme of regulatory T-cell differentiation. Nature 2007, 445:771-775.

8. Zheng Y, Rudensky AY: Foxp3 in control of the regulatory $T$ cell lineage. Nat Immunol 2007, 8:457-462.

9. Hori S, Nomura T, Sakaguchi S: Control of regulatory T cell development by the transcription factor Foxp3. Science 2003, 299:1057-1061.

10. Bennett $\mathrm{CL}$, Christie J, Ramsdell F, Brunkow ME, Ferguson PJ, Whitesell L, Kelly TE, Saulsbury FT, Chance PF, Ochs HD: The immune dysregulation, polyendocrinopathy, enteropathy, X-linked syndrome (IPEX) is caused by mutations of FOXP3. Nat Genet 2001, 27:20-21.

11. Fontenot JD, Rasmussen JP, Gavin MA, Rudensky AY: A function for interleukin 2 in Foxp3-expressing regulatory T cells. Nat Immunol 2005, 6:1142-1151.

12. Li MO, Sanjabi S, Flavell RA: Transforming growth factor-beta controls development, homeostasis, and tolerance of $\mathrm{T}$ cells by regulatory $\mathrm{T}$ cell-dependent and -independent mechanisms. Immunity 2006, 25: 455-471.

13. Fontenot JD, Gavin MA, Rudensky AY: Foxp3 programs the development and function of CD4+CD25+ regulatory T cells. Nat Immunol 2003, 4: 330-336.

14. Chen W, Jin W, Hardegen N, Lei KJ, Li L, Marinos N, McGrady G, Wahl SM: Conversion of peripheral CD4 + CD25- naive T cells to CD4 + CD25+ regulatory $\mathrm{T}$ cells by TGF-beta induction of transcription factor Foxp3. $J$ Exp Med 2003, 198:1875-1886.

15. Marson A, Kretschmer K, Frampton GM, Jacobsen ES, Polansky JK, Maclsaac KD, Levine SS, Fraenkel E, von Boehmer H, Young RA: Foxp3 occupancy 
and regulation of key target genes during T-cell stimulation. Nature 2007, 445:931-935.

16. Xiao S, Jin H, Korn T, Liu SM, Oukka M, Lim B, Kuchroo VK: Retinoic acid increases Foxp3+ regulatory T cells and inhibits development of Th17 cells by enhancing TGF-beta-driven Smad3 signaling and inhibiting IL-6 and IL-23 receptor expression. J Immunol 2008, 181:2277-2284.

17. Mucida D, Park Y, Kim G, Turovskaya O, Scott I, Kronenberg M, Cheroutre H: Reciprocal TH17 and regulatory T cell differentiation mediated by retinoic acid. Science 2007, 317:256-260.

18. Mucida D, Pino-Lagos K, Kim G, Nowak E, Benson MJ, Kronenberg M, Noelle RJ, Cheroutre H: Retinoic acid can directly promote TGF-beta-mediated Foxp3(+) Treg cell conversion of naive T cells. Immunity 2009, 30:471-472. author reply $472-3$.

19. Qin X, Guo BT, Wan B, Fang L, Lu L, Wu L, Zang YQ, Zhang JZ: Regulation of Th1 and Th17 cell differentiation and amelioration of experimental autoimmune encephalomyelitis by natural product compound berberine. $J$ Immunol 2010, 185:1855-63.

20. Xu W, Hou W, Yao G, Ji Y, Yeh M, Sun B: Inhibition of Th1- and enhancement of Th2-initiating cytokines and chemokines in trichosanthin- treated macrophages. Biochem Biophys Res Commun 2001, 284:168-172.

21. Liu Q, Chen T, Chen G, Li N, Wang J, Ma P, Cao X: Immunosuppressant triptolide inhibits dendritic cell-mediated chemoattraction of neutrophils and T cells through inhibiting Stat3 phosphorylation and NF-kappaB activation. Biochem Biophys Res Commun 2006, 345:1122-1130.

22. Hou LF, He SJ, Li X, Yang Y, He PL, Zhou Y, Zhu FH, Yang YF, Li Y, Tang W, et al: Oral administration of artemisinin analog SM934 ameliorates lupus syndromes in MRL/lpr mice by inhibiting Th1 and Th17 cell responses. Arthritis Rheum 2011, 63:2445-55.

23. Huang CF, Lin SS, Liao PH, Young SC, Yang CC: The immunopharmaceutical effects and mechanisms of herb medicine. Cell Mol Immunol 2008, 5:23-31.

24. Bettelli E, Carrier Y, Gao W, Korn T, Strom TB, Oukka M, Weiner HL, Kuchroo VK: Reciprocal developmental pathways for the generation of pathogenic effector TH17 and regulatory T cells. Nature 2006, 441:235-238.

25. Krakauer $T, L i B Q$, Young HA: The flavonoid baicalin inhibits superantigen-induced inflammatory cytokines and chemokines. FEBS Lett 2001, 500:52-55.

26. Lin CC, Shieh DE: The anti-inflammatory activity of Scutellaria rivularis extracts and its active components, baicalin, baicalein and wogonin. Am $J$ Chin Med 1996, 24:31-36.

27. Li BQ, Fu T, Gong WH, Dunlop N, Kung H, Yan Y, Kang J, Wang JM: The flavonoid baicalin exhibits anti-inflammatory activity by binding to chemokines. Immunopharmacology 2000, 49:295-306.

28. Shen YC, Chiou WF, Chou YC, Chen CF: Mechanisms in mediating the anti-inflammatory effects of baicalin and baicalein in human leukocytes. Eur J Pharmacol 2003, 465:171-181.

29. Yang J, Yang $X$, Chu Y, Li M: Identification of Baicalin as an immunoregulatory compound by controlling $\mathrm{T}(\mathrm{H}) 17$ cell differentiation. PLoS One 2011, 6:e17164

30. Fujimoto M, Serada S, Mihara M, Uchiyama Y, Yoshida H, Koike N, Ohsugi Y, Nishikawa T, Ripley B, Kimura A, et al: Interleukin-6 blockade suppresses autoimmune arthritis in mice by the inhibition of inflammatory Th17 responses. Arthritis Rheum 2008, 58:3710-3719.

31. Yang J, Yang X, Zou H, Chu Y, Li M: Recovery of the immune balance between Th17 and regulatory $T$ cells as a treatment for systemic lupus erythematosus. Rheumatology 2011, 50:1366-1372.

\section{Submit your next manuscript to BioMed Central and take full advantage of:}

- Convenient online submission

- Thorough peer review

- No space constraints or color figure charges

- Immediate publication on acceptance

- Inclusion in PubMed, CAS, Scopus and Google Scholar

- Research which is freely available for redistribution 